\title{
İntegral Köprülerde Hareketli Yükler Altında Üstyapı Özelliklerinin Kazık Kuvvetlerine Etkisi
}

\author{
Ömer Fatih YALÇIN"1 \\ ${ }^{1}$ Ístanbul Üniversitesi, Mühendislik Fakültesi, İnşaat Mühendisliği Bölümü, İstanbul
}

Geliş tarihi: 13.03.2017～Kabul tarihi: 31.05 .2017

$\ddot{O} \mathbf{z}$

Bu çalışmada, integral köprülerin kazıklarında oluşan kuvvetlere hareketli yüklerin etkisi, çeşitli üstyapı parametrelerinin değişimleriyle birlikte incelenmiştir. Bu amaçla, birçok üç boyutlu integral köprünün sonlu elemanlar modelleri kurulmuştur. Bu modellerin analizleri AASHTO LRFD hareketli yükleri altında yapılmıştır. Hareketli yükler en kritik etkileri bulabilmek için köprüler üzerinde enine ve boyuna yönde farklı konumlara yerleştirilmişlerdir. Analizlerde köprü uzunluğu, kiriş boyutu ve aralı̆̆ı, kiriş adedi, tabliye kalınlığı ve konsol uzunluğu gibi çeşitli üstyapi parametreleri ele alınmıştır. Sonlu elemanlar analizleri sonucunda farklı parametrelere bağlı kazık kuvvetleri elde edilmiştir. Analizler sonucunda, kiriş tipi ve tabliye kalınlığı dışındaki parametrelerinin kazık kuvvetlerini önemli ölçüde etkiledikleri gözlenmiştir. Ayrıca, ele alınan birçok köprüde yükleme durumlarına bağlı olarak bazı kazıklarda çekme kuvveti oluşmuştur.

Anahtar Kelimeler: İntegral köprü, Üstyapı, Hareketli yük, Kazık kuvveti

\section{Effects of Superstructure Properties on Pile Forces in Straight Integral Bridges under Live Load}

\begin{abstract}
In this study, the effects of truck loads on pile forces for straight integral bridges is investigated together with the variations in superstructure parameters. For this purpose, finite element models of numerous three-dimensional integral bridges are built and the analyses are conducted under AASHTO LRFD live loads. Truck loads are located in various longitudinal and transverse positions on the bridge in order to get the most critical loading. In the analyses, the superstructure parameters such as bridge length, girder type, girder spacing, number of girders, slab thickness and cantilever length are considered and the pile forces for all these bridges are obtained. The analyses results reveal that all the superstructure parameters except girder type and slab length have significant effect on pile forces. Additionally, in almost all bridges, for some load cases tension forces in piles are observed.
\end{abstract}

Keywords: Integral bridge, Superstructure, Live load, Pile force

*Sorumlu yazar (Corresponding author): Ömer Fatih YALÇIN, fyalcin@gmail.com 


\section{GíRiş}

İntegral köprüler genleşme derzi olmayan köprülerdir. Yapısal sistemleri genellikle tek sıra eğilebilir çelik H-kazıklar üzerine oturtulmuş kısa uçayaklardan oluşmaktadır (Şekil 1a). Bu tür köprülerde uçayaklar, tabliye ve kirişlerle birlikte monolitik olarak dökülürler ve bu durum tabliye ve kirişlere burulma rijitliği sağlar. Bu üstyapı-uçayak sürekliliği nedeniyle, hareketli yükler altında üstyapı ve uçayaklar birlikte hareket ederler (Şekil 1b). İntegral köprüler ekonomik ve fonksiyonel olarak geleneksel genleşme derzli köprülere göre birçok avantaja sahiptir [1]. Bunlardan en önemlisi, geleneksel köprülerde bulunan genleşme derzlerinden su, tuz ve buz çözücü kimyasalların sızması nedeniyle köprü elemanlarının zarar görmesinin integral köprülerde yaşanmamasıdır. Ayrıca, integral köprüler inşaat maliyeti ve onarım masrafları açısından daha ekonomik olduğu gibi, rijit çerçeve yapıları nedeniyle de sismik yükler altında daha iyi performans göstermektedir [2, 3]. $\mathrm{Bu}$ tür avantajlarından dolayı integral köprüler Kuzey Amerika'da ve Avrupa'da her geçen gün daha da yaygın olarak inşa edilmekte ve geleneksel köprülerin yerini almaktadırlar [4-6]. Gösterdiği üstünlüklere rağmen bu köprüler henüz ülkemizde kullanılmaya başlanmamıştır ancak, önümüzdeki yıllarda uygulanma potansiyeline sahiptir.

Köprü tasarımında mühendisler, üç boyutlu modeller yerine basitleştirilmiş iki boyutlu modelleri hareketli yük dağılım katsayıları ve verev düzeltme katsayıları ile birlikte kullanmaktadırlar. Ancak bu katsayılar sadece basit mesnetli köprüler için geliştirilmiştir. İntegral köprüler çok yaygın olarak inşa edildikleri halde bunların tasarımı ile ilgili standartlar henüz oluşturulmamıştır. $\mathrm{Bu}$ nedenle, birçok tasarım mühendisi integral köprüleri tasarlarken, üstyap1uçayak sürekliliğini ihmal ederek AASHTO LRFD [7] gibi basit mesnetli köprüler için geliştirilmiş olan standartları kullanmaktadır.

İntegral köprülerin hareketli yükler altındaki davranışının anlaşılmasına yönelik çalışmaların bir bölümünü oluşturan bu çalışmada, hareketli yüklerin integral köprülerdeki kazıklara dağılımı farklı üstyap1 parametrelerine bağlı olarak ve uçayak- dolgu etkileşimi ile birlikte kazık-temel dolgusu etkileşimleri de göz önünde bulundurularak incelenmiştir. Çalışmanın sonuçları, integral köprülerin hareketli yükler altındaki davranışının anlaşılmasına yardımcı olacak ve daha kapsamlı çalışmalar için temel teşkil edecektir.
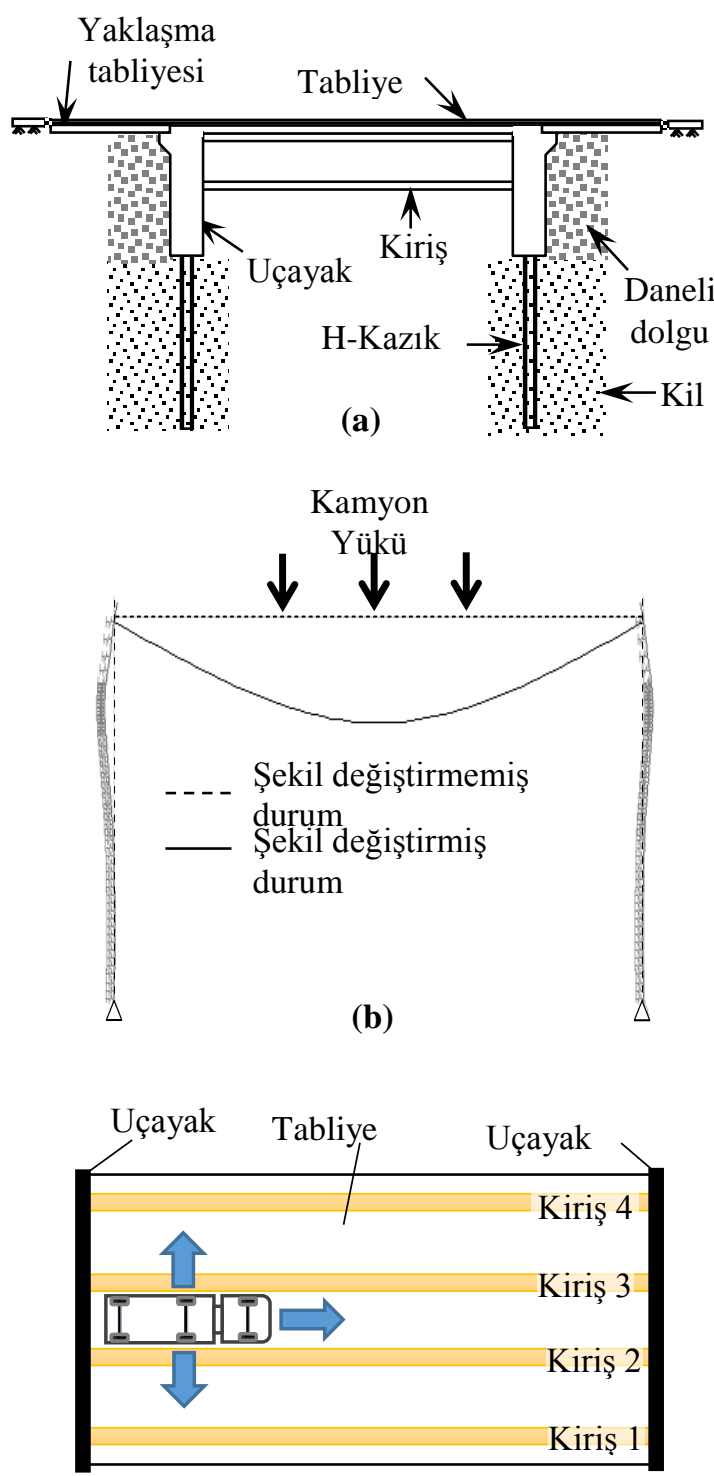

(c)

Şekil 1. İntegral köprünün (a) uzunlamasına kesiti (b) şekil değiştirmiş hali (c) plan görünümü ve kamyon hareket yönleri 


\section{2. ÖNCEKİ ÇALIŞMALAR}

Basit mesnetli köprülerde hareketli yük dağılımları ile ilgili literatürde bulunabilen birçok çalışma yapılmıştır [8-13]. Bu çalışmalardan Zokaie ve arkadaşlarının [11] yaptı̆̆ı çalışmaların sonuçları AASHTO LRFD standardında ilgili bölümün temelini oluşturmaktadır. Bununla birlikte, integral köprüler için benzer çalışmalar ise son yıllarda yapılmaya başlanmıştır. $\mathrm{Bu}$ araştırmaların bir kısmında, üstyapı- uçayak sürekliliğinin ısıl yükler altındaki integral köprülerin performansı üzerine çalışmalar yapılmıştır $[14,15]$. İntegral köprülerde hareketli yük dağılımı ile ilgili çalışmalar yakın zamanda artış göstermiştir [16-23]. Bu çalışmalardan bazılarında Dicleli ve arkadaşları verevsiz integral köprülerin kirişleri ve altyap1 elemanları için hareketli yük dağılım denklemleri geliştirmişlerdir [19, 20]. Bu denklemler, köprü mühendislerine pratikte kullanabilecekleri kolaylıklar sağlamaktadır. Mourad ve Tabsh [17] ise yaptıkları çalışmada, köprülerdeki kazık kuvvetlerini incelemişlerdir. Ancak bu çalışmada sadece iki köprü ele alınmış ve zemin-yap1 etkileşimleri ihmal edilmiştir.

\section{MATERYAL VE METOT}

$\mathrm{Bu}$ çalışmada ilk olarak integral köprülerin modellenmesinde kullanılacak gerçekçi geometrik yapısal ve geoteknik bilgiler ve integral köprülerin sonlu elemanlar yöntemi ile modellenmesi için gerekli gerçekçi modelleme teknikleri belirlenmiştir. Benzer şekilde uçayak-dolgu ve kazık-zemin etkileşimleri uygun şekilde modellenmiştir. Çalışmanın sonraki aşamasında, çeşitli üstyapı özelliklerine (uzunluk, kiriş aralığ1, kiriş tipi, kiriş sayısı, tabliye kalınlığı ve konsol uzunluğu) sahip çok sayıda integral köprünün üç boyutlu yapısal modelleri kurulmuştur. Çok fazla köprü modeli ve yükleme durumu olacağı için, tabliye üzerine kamyon yüklerinin yüklenmesi ve kazıklardaki oluşacak kuvvetlerin alınması otomatik olarak gerçekleştirilmiştir. Bu amaç için, SAP2000 [24] sonlu elemanlar programının Açık Uygulama Arayüzü Programı (OAPI) özelliğini kullanan bir 'Visual Basic for Applications (VBA)' programı Excel'de geliştirilmiştir. VBA programı aracılığıyla, yapısal modeller üzerine enine ve boyuna doğrultuda farklı kamyon konumlarını ve sayılarını göz önüne alarak kamyon veya kamyonlar yerleştirilmiş ve aks yükleri düğüm noktalarına, dügüumlere olan mesafesi ile ters orantılı olarak uygulanmıştır. Tüm modeller VBA ve OAPI aracılığıyla analiz edilerek en büyük kazık eksenel kuvvetleri otomatik olarak derlenmiştir.

\subsection{Kapsam ve Kabuller}

$\mathrm{Bu}$ çalışma simetrik, tek açıklıklı ve kiriş üzeri tabliye şeklindeki integral köprülerle sınırlıdır. Köprülerde, köprü inşaatlarında sıkça kullanılan AASHTO tipi (Tip II-V) öngermeli beton kirişler olduğu varsayılmıştır. İntegral köprülerin uçayakları kazıklarla desteklenmektedir. Kazıkuçayak ve uçayak-üstyapı bağlantıları, pratikte uygulandığı gibi rijit bağlantı olarak kabul edilmektedir [16]. İntegral köprülerde, uçayakların arkasındaki dolgu malzemesinin daneli malzeme, kazık temellerinin ise kil olduğu varsayılmıştır. Bu çalışmada ele alınan integral köprülerde (10-40 m uzunluğa sahip) kazıkların akması beklenmemektedir. Ayrica, kısa ve orta uzunluktaki integral köprülerde 1sısal hareketler çok küçüktür. Bu nedenle, bu tür köprüler için uçayağın arkasında oluşacak boşluk ihmal edilebilecek kadar küçüktür.

\subsection{Köprü Parametreleri}

Hareketli yüklerin integral köprülerin kazıklarına dağılımı üzerindeki etkilerini incelemek için, birçok değişik köprü parametrelerine sahip köprülerin karşılaştırmalı analizleri yapılmıştır. İntegral köprülerin uçayakları $3 \mathrm{~m}$ yüksekliğinde ve 12 m'lik çelik HP-280x85 kazıklar ile mesnetlenmiş kabul edilmiştir. Kazıkların sayısı kirişlerin sayısı ile aynı alınmıştır. Öngermeli beton kirişler için kullanılan betonun mukavemeti $50 \mathrm{MPa}$; tabliye, diyafram ve uçayaklar için kullanılan betonun mukavemeti ise $30 \mathrm{MPa}$ olarak kabul edilmiştir. Uçayakların arkasındaki daneli dolgu malzemesinin birim ağırlı̆g $20 \mathrm{kN} / \mathrm{m}^{3}$ ve kazıkları saran temel zemini drenajsız kayma mukavemeti $\mathrm{C}_{\mathrm{u}}=40 \mathrm{kPa}$ olan orta katı kil olarak 
alınmıştır. Bu parametrik çalışma, uygulamada karşılaşılan bir çok köprü özelliklerini kapsamaktadır.

Analizlerde göz önüne alınan üstyapı özellikleri şunlardır: köprü uzunluğu (L), kiriş aralığı (S), AASHTO öngermeli beton kiriş tipi (GT), Kiriş sayısı (Nb), tabliye kalınlığı (ts) ve konsol uzunluğu (de). Diş kiriş merkezinden korkuluk duvarının yüzüne kadar olan mesafe konsol uzunluğu (de) olarak tanımlanmıştır. Her parametrenin aldığı değerler Çizelge 1 'de verilmiştir. Çizelgede bazı parametreler değişirken sabit tutulan parametrelere sahip köprü referans köprü olarak anılacaktır. $\mathrm{Bu}$ parametrelerin kullanılması ile 19 farklı üç boyutlu yapısal model oluşturulmuştur. $\mathrm{Bu}$ modellerdeki yükleme durumları sayısı ise $8000^{\prime} \mathrm{i}$ aşmaktadır. $\mathrm{Bu}$ yükleme durumları bir veya daha fazla kamyonun iki ve üç boyutlu köprü üzerindeki enine ve boyuna doğrultuda farklı konumlarını içermektedir. Yükleme durumu sayısının bu kadar yüksek olması analizlerin el ile yapılmasını neredeyse olanaksiz hale getirmektedir.

\section{3. Üç-Boyutlu Yapısal Model}

Önceki bölümde bahsedilen köprülerin üç boyutlu yapısal modelleri, sonlu elemanlar programı olan SAP2000 kullanılarak kurulmuş ve analizleri yapılmıştır. Tipik integral köprülerin üç boyutlu modeli Şekil 2'de gösterilmiştir. Köprülerin üstyapılarının ve altyapılarının modellenmesi ile ilgili detaylar takip eden bölümlerde verilmiştir.

\subsection{1. Üstyapının Modellenmesi}

Mabsout ve arkadaşları [13] ve Yousif ve Hindi [8] köprülerin üç boyutlu analizlerinde kullanılacak olan en uygun modeli belirlemek amaciyla literatürde mevcut olan dört farklı sonlu elemanlar modelleme tekniğini $[9,10,12, \quad 25]$ karşılaştırmışlardır. Yaptıkları çalışmalarda, köprülerin sonlu elemanlar kullanılarak modellenmesi için Hays ve arkadaşları [10] tarafından önerilen birinci modelleme tekniği, basit olmasına rağmen daha karmaşık olan diğer üç
Çizelge 1. Ele alınan köprü parametreleri ve değerleri

\begin{tabular}{|c|c|c|c|c|c|}
\hline $\begin{array}{c}L \\
(\mathbf{m})\end{array}$ & $\begin{array}{c}S \\
(\mathbf{m})\end{array}$ & $G T$ & $N_{\mathrm{b}}$ & $\begin{array}{c}\boldsymbol{t}_{\mathrm{s}} \\
(\mathbf{m})\end{array}$ & $\begin{array}{l}d e \\
(m)\end{array}$ \\
\hline $\begin{array}{l}10 \\
20 \\
30 \\
40\end{array}$ & 2,4 & IV & 4 & 0,20 & 0,9 \\
\hline 30 & $\begin{array}{l}\mathbf{1 , 2} \\
\mathbf{2 , 4} \\
\mathbf{3 , 6} \\
\mathbf{4 , 8}\end{array}$ & IV & 4 & 0,20 & 0,9 \\
\hline 30 & 2,4 & $\begin{array}{c}\text { II } \\
\text { II } \\
\text { IV } \\
\text { V }\end{array}$ & 4 & 0,20 & 0,9 \\
\hline 30 & 2,4 & IV & $\begin{array}{l}4 \\
5 \\
6 \\
7\end{array}$ & 0,20 & 0,9 \\
\hline 30 & 2,4 & IV & 4 & $\begin{array}{l}0,15 \\
0,20 \\
0,25 \\
0,30\end{array}$ & 0,9 \\
\hline 30 & 2,4 & IV & 4 & 0,2 & $\begin{array}{c}\mathbf{- 0 , 3} \\
\mathbf{0 , 3} \\
\mathbf{0 , 9} \\
\mathbf{1 , 5}\end{array}$ \\
\hline
\end{tabular}

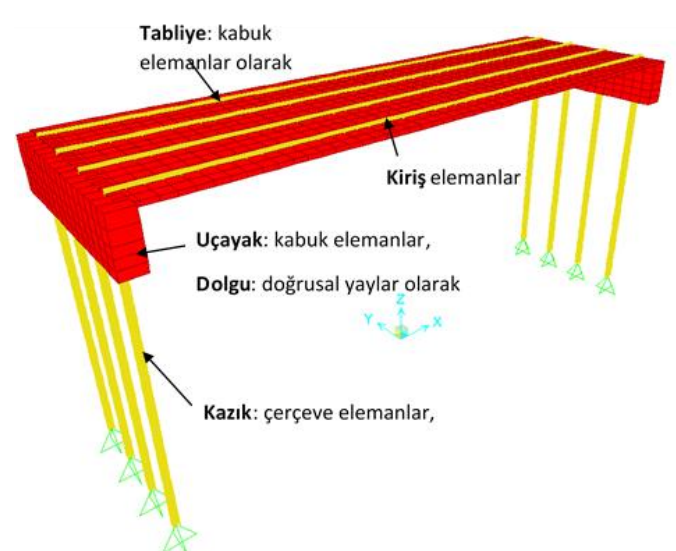

Şekil 2. Tipik bir integral köprünün 3 boyutlu yapisal modeli 
modelle benzer sonuçlar vermesinden dolayı tavsiye edilmektedir. Bu çalışmada da integral köprülerin üst yapısı bu modelleme tekniği kullanılarak modellenecektir. Tabliye için, uçayağa paralel olan paralelkenar kabuk elemanlar, kirişler için de 3 boyutlu kiriş elemanlar kullanılacaktır (Şekil 2). Bu elemanların kullanımı kamyon yüklerinin yerleştirilmesinde ve kabuk elemanların otomatik olarak üretilmesinde kolaylık sağlayacaktır. Paralelkenarların uzunlamasına doğrultuda kenar uzunlukları ve enlemesine doğrultudaki genişlikleri 0,6 m olarak alınmıştır.

\subsubsection{Altyapının Modellenmesi}

Bu çalışmada, uçayaklar kesme etkilerinin göz önüne alınabilmesi için Mindlin kabuk elemanlar [26] kullanılarak ve kazıklar da üç boyutlu çerçeve elemanlarla modellenmiştir. Uçayak, tabliye ile uyumlu olması amacıyla, enine yönde kenarı 0,6 m uzunluğunda olan dikdörtgen elemanlara bölünmüştür. Bununla birlikte, düşey yöndeki boyutları, seçilen kiriş tipine ve rijit tabliye-uçayak bağlantısında olup olmama durumuna göre 0,400 - 0,575 m arasında değişmektedir. Modeller üzerinde yapılan sonlu eleman boyutlarının yakınsaklık çalışmaları, kullanılan sonlu eleman ağının uygun olduğunu göstermiştir. İntegral köprülerdeki altyapı modellemesi ile ilgili daha detaylı bilgiler Dicleli ve Erhan [18] tarafindan verilmiştir.

\subsubsection{Yapı - Zemin Etkileşiminin Modellenmesi}

Hareketli yük etkisi altında, verevli integral köprünün yatay yer değiştirmesi küçük olduğundan dolayı, gerçekte doğrusal olmayan temel zemini-kazık ve dolgu-uç ayak etkileşimleri, doğrusal olarak modellenmiştir. Temel ZeminiKazık Etkileşimi için zemin elastisite modülü Eşitlik 2'deki gibi alınmıştır [18].

$$
E_{s}=\frac{9 C_{u}}{5 \varepsilon_{50}}
$$

Eşitlik 2'de $\mathrm{C}_{\mathrm{u}}$ drenajsız kayma mukavemetini, $\varepsilon_{50}$ ise $\% 50$ mukavemete karşılık gelen birim şekil değiştirmeyi göstermektedir. İncelenen köprülerdeki kazık zemini için $\mathrm{C}_{\mathrm{u}}=40 \mathrm{kPa}$ ve $\varepsilon_{50}=0,01$ olarak alınmıştır. Kazık-zemin etkileşimi, kazık boyunca belirli aralıklarla yerleştirilen düğüm noktalarına doğrusal yatay yaylar bağlanarak modellenmiştir. $\mathrm{Bu}$ modelde elastik yay sabiti, zemin elastisite modülü ile düğüm noktaları arasındaki uzaklığın ve kazık çapının çarpımından elde edilir. Uç ayak- dolgu etkileşimi için, yay katsayısı aşağıdaki Eşitlik 1'e göre hesaplanır: [18].

$k_{s h}=\frac{14500}{H} \cdot z$

Burada H uçayağın yüksekliği ve $z$ 'de uçayağın tepesinden olan mesafedir. Dolgu-uç ayak etkileşimini modellemek için, uçayağın yüksekliği boyunca belirli aralıklarla düğüm noktaları yerleştirilmiş ve bu noktalara yatay doğrusal yaylar bağlanmıştır. $\mathrm{Bu}$ yayların rijitliği, uçayağın yüksekliği boyunca yerleştirilmiş olan düğüm noktalarında hesaplanan $\mathrm{k}_{\mathrm{sh}}$ ile düğüm noktaları arasındaki alanın çarpımıyla bulunmuştur. Yukarıda açıklanan dolgu rijitliği modeli, sadece üstyapının merkezinin altında kalan uçayak bölümünde dolgunun pasif direncini göz önüne almaktadır. Diğer bir ifade ile sadece hareketli yükün harekete geçirdiği dolgunun direnci göz önüne alınmaktadır. Dicleli ve Erhan [18] integral köprülerdeki yapı-zemin etkileşimi ile ilgili daha detaylı bilgiler vermektedir.

\subsection{Hareketli Yük Modeli}

$\mathrm{Bu}$ çalışmada yapılan analizlerde, AASHTO LRFD ile uyum sağlamak bakımından, AASHTO HL-93 hareketli yükü kullanılmıştır. HL-93 yükü, $35 \mathrm{kN}$ ağırlığında ön dingilden, bu dingile 4,3 m uzaklıkta olan $145 \mathrm{kN}$ 'luk orta dingilden ve orta dingile $4,3 \mathrm{~m}$ ile $9,0 \mathrm{~m}$ arasında değişen mesafelerde bulunan $145 \mathrm{kN}$ 'luk arka dingilden oluşur (Şekil 3a). Enlemesine birden fazla kamyonun yerleştirildiği durumlarda kamyonlar arasındaki ve kamyonla köprü kenarı arasındaki mesafe sınırları Şekil 3b'de gösterilmiştir. Kamyonlar enine ve uzunlamasına yönde kabuk elemanların bu yöndeki boyutları ile uyumlu olmaları için $0,6 \mathrm{~m}$ adımlarla hareket ettirilmektedir. 

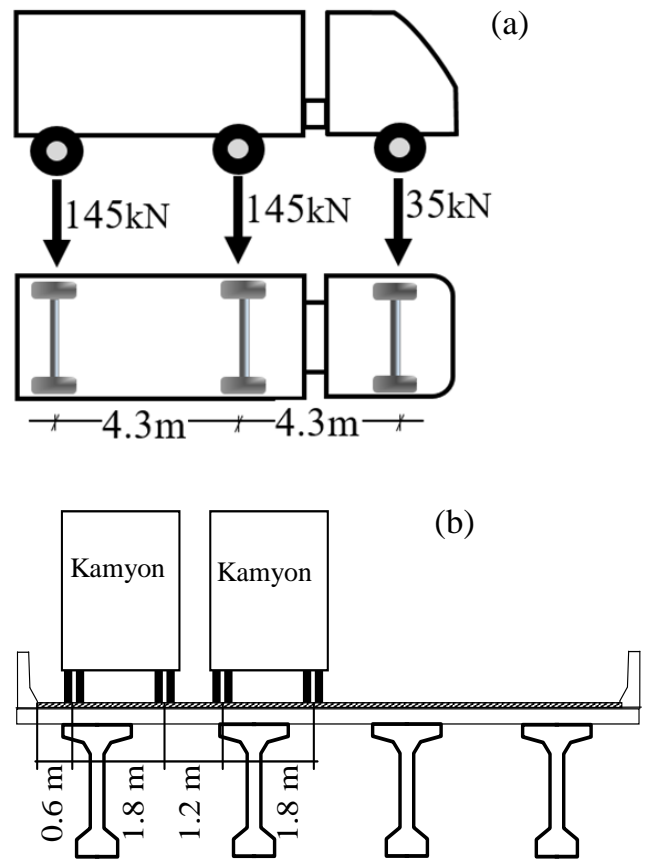

Şekil 3. (a) AASHTO LRFD, HL-93 tasarım kamyon yükü (b) Köprü üzerinde yan yana yerleştirilmiş kamyonlar için minimum mesafeler

\subsection{Parametrik Çalışmalar}

Çalışmanın doğasından dolayı, farklı parametrelere sahip birçok integral köprü modelleri ve bu modellere uygulanması gereken çok fazla yükleme durumları olması nedeniyle, otomatikleştirilmiş bir süreç kullanılması zorunludur. $\mathrm{Bu}$ amaçla, köprü modellerinin değiştirilmesi, analiz edilmesi, sonuçların alınması, işlenmesi ve tablolanması için, Excel içerisinde yazılan ve SAP2000 OAPI (Open Application Programming Interface) arayüzünü kullanan bir VBA (Visual Basic for Applications) programı yazılmıştır. OAPI arayüzü, köprü modelini açarak bir ve birden fazla (köprü genişliği boyunca ne kadar kamyon sığıyorsa o kadar) kamyonun yükleme durumlarını oluşturmak; tüm modelleri koşturmak ve analiz sonuçlarını alıp maksimumlarını bulmak gibi zahmetli ve zaman alıcı işlemlerin gerçekleştirilmesini mümkün kılmaktadır.
VBA programı ve Excel sayfaları sonlu elemanlar modellerini hazırlamak ve SAP2000'den gerekli sonuçları alıp tablolamak için birlikte kullanılmışlardır. Program girdi olarak her bir köprünün parametrelerini (uzunluk, kiriş tipi, kiriş aralığı, tabliye kalınlığı vs.) Excel'den almaktadır. Program bu parametreleri kullanarak yükleme durumlarını isimlendirir ve ilgili yükleme durumuna uygun kamyon tekerlek yüklerini düğüm noktalarına uygular. Yükleme durumları, tek kamyon veya köprü genişliğine göre enine yönde ne kadar kamyon alıyorsa (geniş köprülerde 5 kamyona kadar çıkmaktadır) o kadar kamyon yüklemesini içerir. Ayrıca, maksimum etkiyi bulabilmek için bu kamyonların enine yöndeki tüm olası konumları da yükleme durumlarının içerisinde olmalıdır. Kritik kazık kuvvetlerini verecek yükleme durumunun kamyonun arka aksının tam kazık üzerinde olduğu durum olarak öngörülmektedir. Ancak, yapılan hassasiyet analizlerinde özellikle birden çok kamyon yüklemesinde kritik etkiler kamyon uzunlamasına yönde köprü içerisinde iken oluştuğu belirlenmiştir. $\mathrm{Bu}$ nedenle kamyonlar enine yönde olduğu gibi uzunlamasına yönde de köprü ucundan köprü ortasına kadar gezdirilmiştir. Kamyon tekerlek yükleri genellikle kabuk elemanların düğüm noktaları ile çakışmamaktadır. Bu durumda yük en yakın düğümlere uzaklıkları ile ters orantılı olarak dağıtılır. Köprünün parametreleri değiştikçe yüklerin aktarılacağı düğümler ve şiddetleri de değişmektedir. Hareketli yük etkileri, üç boyutlu analiz sonuçlarından elde edilir. Daha sonra program her bir köprüdeki tüm kazık kuvvetlerini alarak Excel sayfasına yazmaktadır. Şekil 4'de VBA programının genel çerçevesi verilmektedir.

$\mathrm{Bu}$ çalışma kapsamındaki tüm bu olası yükleme durumlarının belirlenmesi ve düğüm noktalarına yüklerin uygulanması ve sonuçların alınması gibi elle yapılması çok yorucu ve zaman alıcı olan bu işlemler, OAPI yardımı ile Intel i7 işlemcili bir PC'de yaklaşık 6 saat gibi kısa sayılabilecek bir sürede gerçekleştirilebilmektedir. 
Yükleyici:

- Bu altprogram, istenilen köprülere, köprü parametrelerini okuduktan sonra;

-Öncelikle köprüye kaç kamyon sığacağını belirler

-Daha sonra yerleştirilecek kamyonların tekerlek yüklerinin uygulanacağı düğüm noktalarının koordinatlarını ve yük miktarını hesaplar. Kritik kamyon durumunu belirlemek için, kamyon tekerlek yüklerini hem enine yönde hem de uzunlamasına yönde hareket ettirir

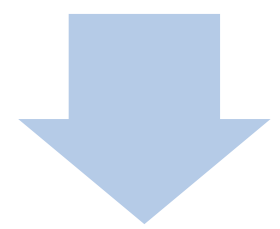

\section{Sonuçlar:}

- Bu alt program, yüklemesi yapılmış olan modellerin analizini yaptırır. Daha sonra sonuç alınacak kazıkları seçer ve kazıklardaki eksenel kuvvetleri her bir yükleme durumu için alır. Maksimum ve minimum etkileri, model ismi, yükleme durumu, lokasyonu gibi bilgilerle birlikte tablo halinde Excel sayfasina raporlar.

Şekil 4. Hazırlanan VBA alt programları ve işlevleri

\section{BULGULAR}

Parametrik analizlerin sonuçlarından elde edilen kazık kuvvetleri takip eden bölümlerde sunulmaktadır. İlgili şekillerde, tek bir kamyon yüklemesi durumundaki en küçük ve en büyük kazık kuvveti sonuçları Min-1 ve Maks-1 ifadeleri ile belirtilmiştir. Benzer şekilde, iki veya daha fazla șeridin yüklü olduğu durumlar Min-2 ve Maks-2 ile gösterilmiş̧ir. Bu terimlerdeki Min ifadesi minimum kuvveti (en büyük basınç kuvvetini), Maks ifadesi maksimum kuvveti (en küçük basınç veya en büyük çekme kuvvetini), ifadelerin ardındaki rakam da kamyon sayısını temsil etmektedir. Maks ile temsil edilen kuvvetlerin incelenmesinin nedeni, kazıklarda oluşabilecek çekme kuvvetlerini görebilme imkanı elde etmek içindir.

Takip eden bölümlerde, hassasiyet analizleri, kazıklarda oluşan eksenel kuvvetlerin farklı üstyapı özelliklerine bağlı değişimleri ve hareketli yüklerin kazıklara dağılımı verilmektedir. Köprüler için göz önünde bulundurulan parametreler Çizelge 1'de verilmiştir.

\subsection{Tesir Çizgisi Analizleri}

En kritik kazık kuvvetlerinin kamyon tam olarak uçayak üzerinde iken oluştuğu sezgisel olarak bulunabilir. Bunu incelemek için yapılan tesir çizgisi analizlerinde görülmüştür ki, bu durum kazıklarda oluşan minimum (en büyük basınç kuvveti) etki için doğrudur. Ancak, maksimum kuvvet diye ifade ettiğimiz ve bazen çekme kuvveti olarak ortaya çıkan kuvvet durumunda, en kritik etki kamyon uzunlamasına yönde daha içerideyken oluşabilmektedir. Örneğin, $\mathrm{de}=1,5 \mathrm{~m}$ olan köprüde, iki kamyonun uzunlamasına yönde

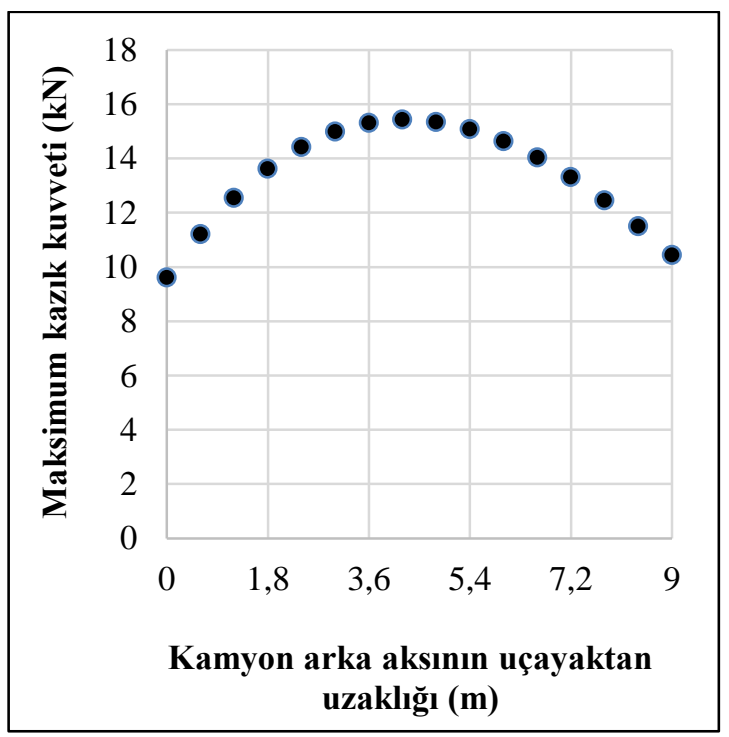

Şekil 5. Kamyon arka aksının uçayaktan uzaklığı ile maksimum kazık kuvveti arasındaki ilişki 
hareketi ile kazıklarda oluşan maksimum kuvvetin değişimi Şekil 5 'te gösterilmiştir. Bu nedenle, en kritik etkileri elde edebilmek için, kamyon yükleri köprü üzerinde enine yönde olduğu gibi boyuna yönde de farklı konumlara kaydırılmaktadır (bkz. Şekil 1c).

Tek bir kamyonun referans köprünün en kenarında ve en ucunda dururken yükleme noktasının altındaki sıradaki kazıklarda oluşturduğu kuvvetler Şekil 6'da verilmiştir. Şekilden de görüleceği gibi yükün yakın olduğu kazıklarda basınç kuvveti oluşmakta ve yüke en uzak kazıkta da çekme kuvveti oluşmaktadır. $\mathrm{Nb}=6$ olan köprüde kamyon enlemesine doğrultuda gezdirilirken kazıklarda oluşan en büyük ve en küçük kuvvetler de Şekil 7a ve $7 b$ 'de verilmiştir. Köprü simetrik olduğu için kazık kuvvetleri de simetrik çıkmıştır. En içteki iki kazık hariç diğer tüm kazıklarda çekme kuvveti oluştuğuna dikkat edilmelidir. En diştaki kazıkların her zaman en kritik etkilere maruz kaldıkları tüm köprüler için tespit edilmiştir. Benzer nedenlerledir ki, AASHTO LRFD basit mesnetli köprülerde hareketli yük dağılım katsayılarını hesaplarken en dıştaki kirişleri ayrı olarak ele almaktadir.

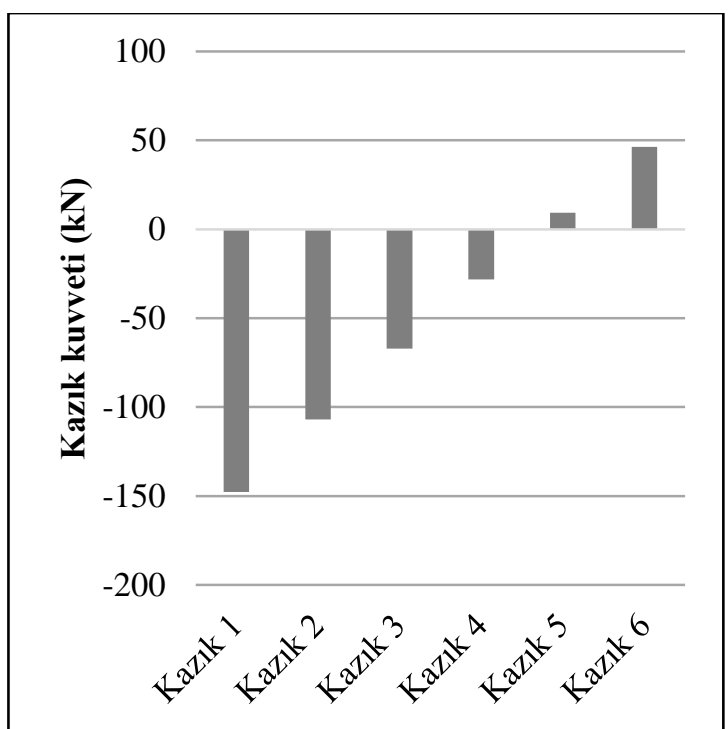

Şekil 6. 1 kamyon yüklemesi durumunda, kamyon en kenarda dururken kazıklarda oluşturduğu kuvvetler

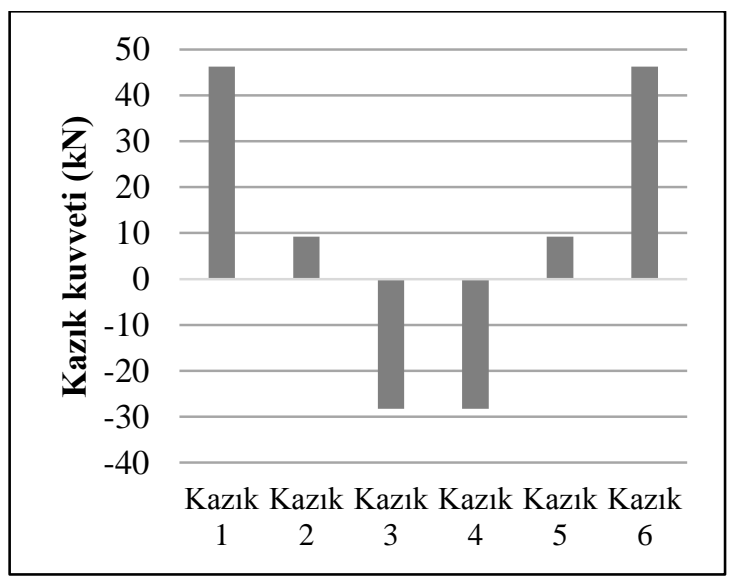

(a)

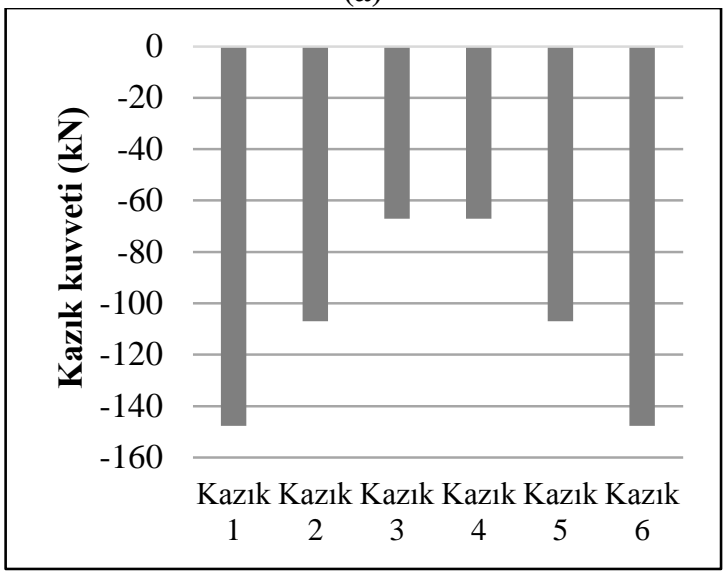

(b)

Şekil 7. 1 kamyon yan doğrultuda gezerken her bir kazıkta oluşturduğu (a) en büyük kuvvetler (b) em küçük kuvvetler

\subsection{Köprü Uzunluğunun Etkisi}

Tesir çizgisi analizleri sonuçlarından elde edilen bilgilere göre oluşturulan kamyon yüklemeleri senaryoları, bu bölümde farklı uzunluklara sahip köprüler için uygulanmıştır. Kazıklarda oluşan en büyük (Maks) ve en küçük (Min) kuvvetlerin, köprü uzunluklarına göre değişimleri Şekil 8'de kümelenmiş sütun grafikleri ile gösterilmiştir. Referans köprü için bulunan değerler bu ve bundan sonraki bölümler için gri sütunlarla gösterilmektedir. Şekilden de görüleceği üzere köprü uzunluğu parametresi kazık kuvvetlerini önemli ölçüde etkilemektedir. Beklendiği gibi, 
köprü uzunluğu arttıkça, kamyon yükleri köprünün bir ucundaki kazıklar üzerinde yoğunlaşmakta ve kazık kuvvetleri artmaktadır. En kısa ve en uzun köprü arasındaki fark, Min-1 için \%50'den fazla olmuştur. Yan yana yerleştirilen kamyon sayısının artması durumunda, ele alınan farklı uzunluğa sahip tüm köprülerde, 2 kamyon için tek kamyona göre artış gözlendiği halde 3 kamyon için 2 kamyona göre azalma olmuştur. $\mathrm{Bu}$ durum da 3 kamyon durumunda kamyon yüklerinin kazıklara daha üniform yayılmasından kaynaklanmaktadır.

Diğer bir önemli husus da tek kamyon yüklemesi durumunda yükten uzak olan kazıklarda çekme kuvveti oluşmasıdır. Bu durum köprü tabliyesinin o noktalarda yukarı doğru şekil değiștirmesinden kaynaklanmaktadır. 2 ve 3 kamyon yüklemelerinde ise herhangi bir kazıkta çekme gözlenmemiştir.

\subsection{Kiriş Tipinin ve Tabliye Kalınlığının Etkisi}

Kamyon yüklerinin kazık kuvvetleri üzerindeki etkileri, farklı kiriş tiplerine ve farklı tabliye kalınlıklarına sahip köprüler için Şekil 9a ve 9b'de sırasıyla verilmiştir. Kiriş tipi (GT) ve özellikle tabliye kalınlığı (ts) parametrelerinin etkileri, beklendiği üzere, çok küçük olmuştur. Bu nedenle, bu parametrelerin, integral köprülerdeki kazık kuvvetleri için geliştirilecek bağıntılarda kullanılmasına gerek yoktur.

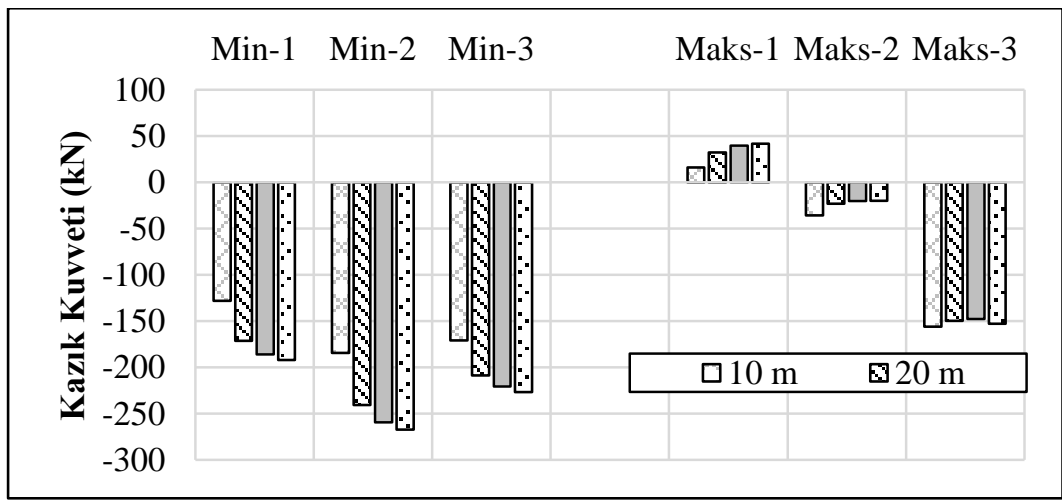

Şekil 8. Köprü uzunluğunun (L) kazık kuvvetleri üzerindeki en küçük ve en büyük etkileri
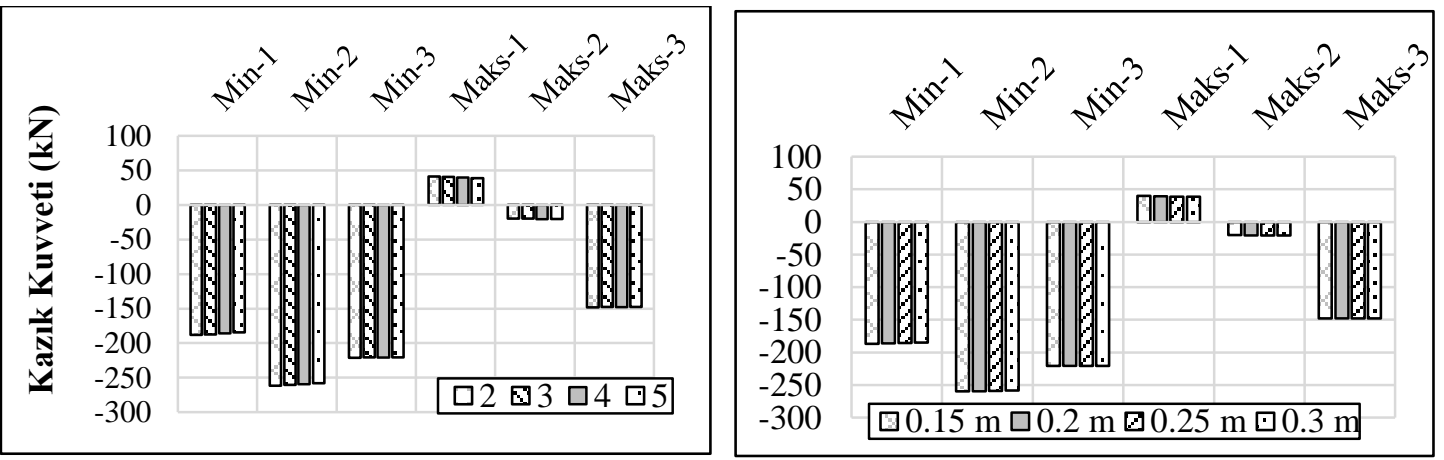

Şekil 9. (a) Kiriş tipinin (GT) ve (b) tabliye kalınlığının (ts) kazık kuvvetleri üzerindeki en küçük ve en büyük etkileri

\subsection{Kiriş Aralığının Etkisi}

Kirişler arasındaki aralığın artması köprü genişliğinin artmasına neden olmaktadır. Ayrıca, bu artış köprü üzerindeki yüklerin belirli kirişlerde ve kazıklarda yoğunlaşmasına neden olmakta ve bu elemanlardaki iç kuvvetleri artırmaktadır. Bu durum kazık kuvvetleri için Şekil 10'da açıkça 
görülmektedir. $\mathrm{S}=1,2 \mathrm{~m}$ aralığa sahip köprülerde 2 veya daha fazla kamyon yan yana yerleştirilememektedir. Bununla birlikte $S=4,8 \mathrm{~m}$ aralığa sahip köprülerde ise 5 kamyona kadar yükleme yapılabilmektedir. Şekilden de anlaşılacağı üzere, kiriş aralığı arttıkça en küçük kazık kuvvetleri de (Min) mutlak değerce artmaktadır. Kamyon sayısı ile birlikte kiriş aralığının aynı zamanda artması bu kuvvetlerdeki artışı daha da yükseltmektedir. Tüm incelenen parametreler içerisinde en büyük basınç kuvvetinin oluştuğu durum $\mathrm{S}=4,8 \mathrm{~m}$ olan köprüde gerçekleşmiştir. Ayrıca, kiriş aralığı $\mathrm{S}=3,6$ ve 4,8 m olan köprülerde 2 kamyon yüklemesi durumunda da kazıklarda çekme kuvveti oluşabilmektedir. Yukarıda bahsedilen hususlardan dolayı, bu parametrenin kazık kuvvetleri üzerinde çok önemli değişikliklere neden olabileceği söylenebilir.

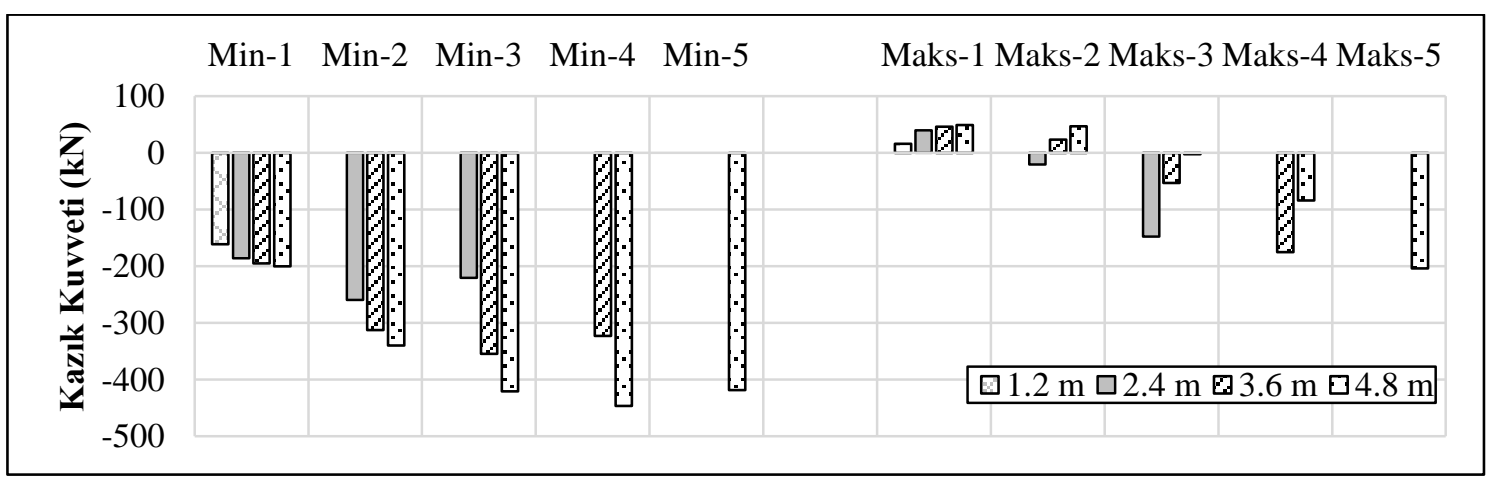

Şekil 10. Kiriş aralığının (S) kazık kuvvetleri üzerindeki en küçük ve en büyük etkileri

\subsection{Kiriş Sayısının Etkisi}

Kiriş sayısı parametresi de köprü genişliğini artıran bir parametredir. Ancak bu artışla birlikte, kazık sayısı da arttığı için, bu parametrenin kazık kuvvetleri üzerindeki etkisi kiriş aralı̆̆ gibi olmamıştır. Şekil 11'den de gözlemleneceği gibi, en küçük kazık kuvvetlerinin (Min) büyüklüğü, kiriş sayısı arttıkça 1 ve 2 kamyon için azalmakta ancak 3 ve 4 kamyon için artmaktadır. Köprü genişliği elverdiği için bu parametre için yan yana yerleştirilen kamyon adedi 5'e kadar artırılabilmiştir. En büyük kazık kuvvetleri (Maks) incelendiğinde ise kiriş sayısının artması ile 3 kamyon yüklemesi durumunda dahi kazıklarda çekme kuvveti oluşabilmektedir. Bu nedenle, Bu parametrenin değişiminin kazık kuvvetlerine etkisi mutlaka kamyon adedi ile birlikte değerlendirilmelidir.

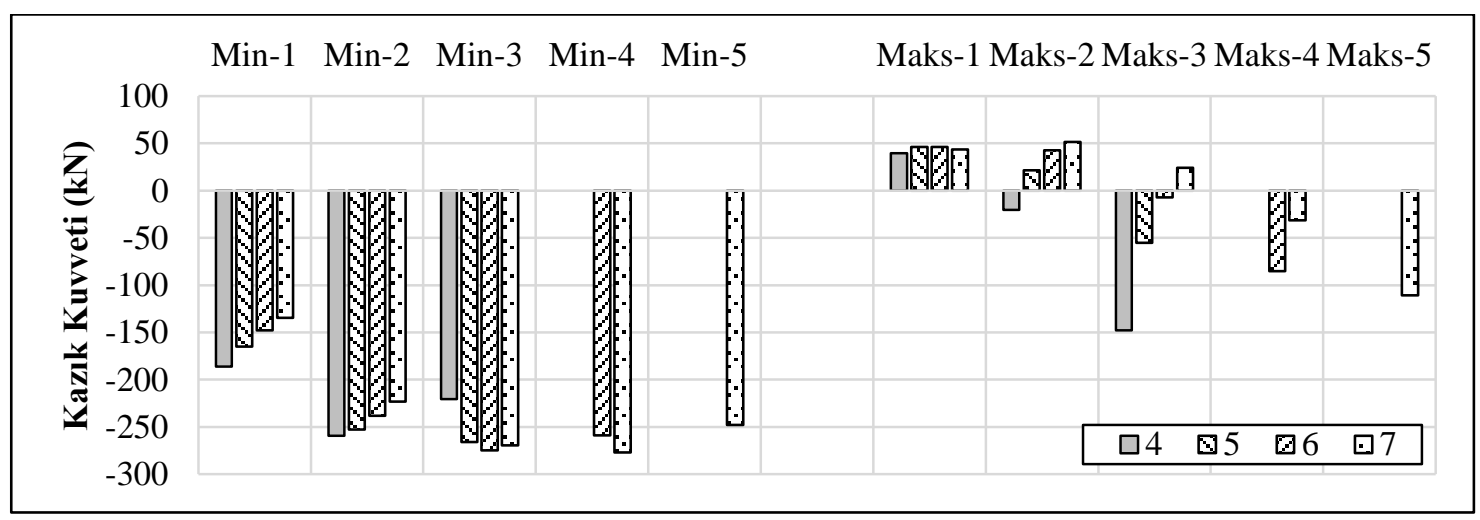

Şekil 11. Kiriş sayısının (Nb) kazık kuvvetleri üzerindeki en küçük ve en büyük etkileri 


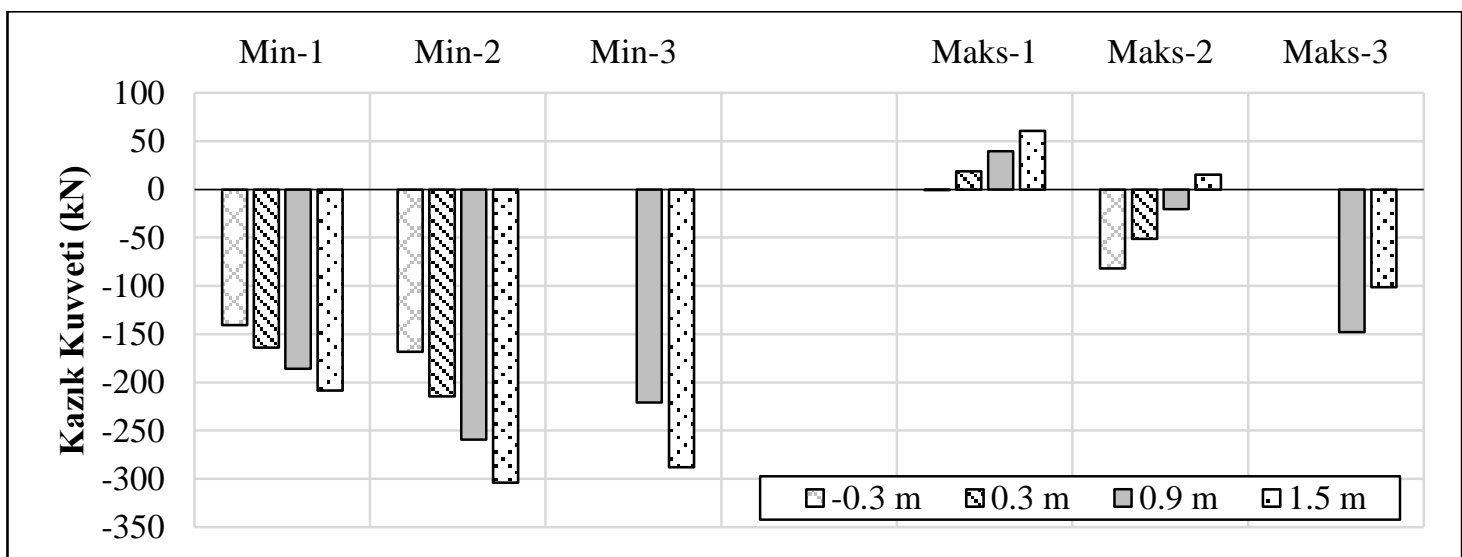

Şekil 12. Konsol uzunluğunun (de) kazık kuvvetleri üzerindeki en küçük ve en büyük etkileri

\subsection{Konsol Uzunluğunun Etkisi}

Konsol uzunluğu parametresinin etkileri en çok diş kazıklarda görülmektedir. $\mathrm{Bu}$ parametrenin değerinin artmasıyla kamyon köprünün dişına doğru daha fazla hareket edebilmekte ve diş kazı̆̆a daha çok eksenel kuvvet gelmesine neden olmaktadır. Bu durum Şekil 12'den de açıkça görülmektedir. Konsol uzunluğunun $-0,3 \mathrm{~m}$ ve $0,3 \mathrm{~m}$ olduğu köprülerde köprü üzerine sadece 2 kamyon yerleştirilebilmektedir. Şunu da belirtmek gerekir ki, tüm köprüler içerisinde, en büyük kazık çekme kuvveti konsol uzunluğunun en fazla olduğu durumda gerçekleşmiştir.

\section{DEĞERLENDİRME}

$\mathrm{Bu}$ çalışmada integral köprüler üzerinde farklı hareketli yük birleşimleri oluşturularak, üstyap1 parametrelerinin kazıklarda oluşan eksenel kuvvetlere etkileri incelenmiştir. Hareketli yükler olarak AASHTO LRFD tasarım yükü olan HL-93 yükü kullanılmıştır. İntegral köprüler için tasarım yönetmelikleri henüz oluşturulmamıştır. Dolayısıyla bu çalışmanın sonuçları, pratikte köprü tasarımcıları tarafından ve ileride geliştirilecek hareketli yük dağılım katsayısı formülleri için kullanılabilecektir. Çalışmadan elde edilen sonuçlar aşağıdaki gibi özetlenebilir:

1. Hareketli yükler altında, kazıklarda basınç kuvvetinin yanında çekme kuvveti de oluşabilmektedir.
2. Kazıklardaki en büyük kuvvetler (basınç veya çekme) her zaman diş kazıklarda oluşmaktadır.

3. Kiriş tipi (GT) ve tabliye kalınlı̆̆ parametrelerindeki farklılıkların kazık kuvvetleri üzerine etkisi çok küçük olmuştur.

4. Diğer parametreler olan köprü uzunluğu (L), kiriş aralığı $(\mathrm{S})$, kiriş sayısı $(\mathrm{Nb})$ ve konsol uzunluğunun (de) kazık kuvvetleri üzerine etkisi ise oldukça belirgindir. Bunların içerisinde en büyük basınç kuvvetleri $\mathrm{S}$ parametresinin artmasıyla gerçekleşmektedir. En büyük çekme kuvveti ise konsol uzunluğunun en büyük olduğu köprüde oluşmuştur ( $\mathrm{de}=1,5 \mathrm{~m})$.

\section{KAYNAKLAR}

1. Burke, M.P. Jr., 2009. Integral and Semi-Integral Bridges, John Wiley and Sons, West Sussex, UK

2. Franchin, P., Pinto, P.E., 2014. Performancebased Seismic Design of Integral Abutment Bridges, Bulletin of Earthquake Engineering, 12, 939-60.

3. Erhan, S., Dicleli, M., 2015. Comparative Assessment of the Seismic Performance of Integral and Conventional Bridges with Respect to the Differences at the Abutments, Bulletin of Earthquake Engineering, 13, 653-77. 
4. White, H., Pétursson, H., Collin, P., 2010. Integral Abutment Bridges: the European Way, Practice Periodical on Structural Design and Construction, 15, 201-8.

5. David, T.K., Forth, J.P., Ye, J., 2014. Superstructure Behavior of a Stub-Type Integral Abutment Bridge, Journal of Bridge Engineering, 19, 04014012.

6. Feldmann, M., Pak, D., Hechler, O., Martin, P.O., 2011. A Methodology for Modelling the Integral Abutment Behaviour of NonSymmetrically Loaded Bridges, Structural Engineering International, 21, 311-9.

7. AASHTO LRFD Bridge Design Specifications. $2014,6^{\text {th }}$ ed. Washington DC.

8. Yousif, Z., Hindi, R., 2007. AASHTO-LRFD Live Load Distribution for Beam-and-slab Bridges: Limitations and Applicability, Journal of Bridge Engineering, 12, 765-73.

9. Imbsen, R.A., Nutt, R.V., 1978. Load Distribution Study on Highway Bridges using STRUDL Finite Element Analysis Capabilities, Proceedings of Conference on Computing in Civil Engineering, ASCE, New York.

10. Hays, C.O., Sessions, L.M., Berry, A.J., 1986. Further Studies on Lateral Load Distribution using a Finite Element Method, Transportation Research Record, Vol. 1072, pp. 6-14.

11.Zokaie, T., 2000. AASHTO-LRFD Live Load Distribution Specifications, Journal of Bridge Engineering, Vol. 5, pp. 131-138.

12. Tarhini, K.M., Frederick, R.G., 1992. Wheel Load Distribution in I-girder Highway Bridges, Journal of Structural Engineering, Vol. 118, pp. 1285-95.

13. Mabsout, M.E., Tarhini, K.M., Frederick, G.R., Tayar, C., 1997. Finite Element Analysis of Steel Girder Highway Bridges, Journal of Bridge Engineering, 2, 83-7.

14. Dicleli, M., Albhaisi, S.M., 2003. Maximum Length of Integral Abutment Bridges Supported on Steel h-piles Driven in Sand, Engineering Structures, 25, 1491-504.

15. Brooke Q.H., Civjan A.S., 2016. Parametric Study on Effects of Pile Orientation in Integral Abutment Bridges, Journal of Bridge Engineering, 04016132.

16. Husain, I., Bagnariol, D., 1996. Integral-abutment Bridges, Ontario Ministry of
Transportation Report SO-96-01, St. Catharines, Ontario, Canada.

17. Mourad, S., Tabsh, W.S., 1998. Pile Forces in Integral Abutment Bridges Subjected to Truck Loads, Transportation Research Record: Journal of the Transportation Research Board 1633, 77-83.

18. Dicleli, M., Erhan, S., 2008. Effect of Soil and Substructure Properties on Live Load Distribution in Integral Abutment Bridges, Journal of Bridge Engineering, 13, 527-39.

19. Dicleli, M., Erhan, S., 2009. Live Load Distribution Formulae for Single Span Prestressed Concrete Integral Abutment Bridge Girders, Journal of Bridge Engineering, 14, 472-486.

20. Erhan, S., Dicleli, M., 2009. Live Load Distribution Equations for Integral Bridge Substructures, Engineering Structures, 31, 1250-64.

21. Yalcin, O.F., Dicleli, M., 2013. Comparative Study on the Effect of Number of Girders on Live Load Distribution in Integral Abutment and Simply Supported Bridge Girders, Advances in Structural Engineering, 16, 1011-34.

22. Dicleli, M., Yalcin, O.F., 2014. Critical Truck Loading Pattern to Maximize Live Load Effects in Skewed Integral Bridges, Structural Engineering International, 2, 265-74.

23. Yalcin, O. F., 2017. A Comparative Study of Live Load Distribution in SKEWED Integral and Simply Supported Bridges, KSCE Journal of Civil Engineering, 1-13.

24.SAP2000, 2014. Integrated Finite Element Analysis and Design of Structures. Berkeley (CA): Computers and Structures Inc.

25. Brockenbrough, R.L., 1986. Distribution Factors for Curved I-girder Bridges. Journal of Structural Engineering, 112, pp. 2200-15.

26. Cook, R.D., 1995. Finite Element Modeling for Stress Analysis, New York, John Wiley \& Sons. 